\title{
Locally advanced pancreatic cancer-a resectable disease?
}

Pancreatic cancer (PC) is undoubtedly among the deadliest cancers and most of the research publications start with this dismal fact. The 5-year survival has improved two to three times over the past decades. However, this hardly makes any difference as it still stays below the $10 \%$ threshold attributable to the dominating later cancer stage at diagnosis. At the same time the survival for all cancer types is above $60 \%$ (1). Contemporary oncologic chemo-radiotherapy and targeted immunotherapy have made possible to improve the prognosis of many cancer types even in their disseminated stages. Unluckily, that does not count for PC, which remains relatively insensitive to all new treatments. This overwhelmingly disappointing and pessimistic truth about PC resonates not only in poorer investment in research, reported to correlate proportionately with cancer survival, but also in the sceptic attitude to emerging treatment approaches.

Surgical resection reckons as the only chance for PC cure, especially reserved for not more than $20 \%$ of the patients whose tumors have limited vascular contact. The recommendation itself to resect PC does not build on high-level scientific evidence as there are no randomized trials proving surgery's superiority above medical treatment. Yet, the difference in survival with the two approaches, seen in early observational studies, is so big that it would be ethically extraneous to perform such studies. The unfortunate locally advanced pancreatic cancer (LAPC), even if not disseminated, exhibits outcome not much different from metastatic disease when treated in the same way, by oncologic therapy. Over the past few years retrospective observational series repeatedly report that in selected LAPC patients long term survival can be achieved after neoadjuvant therapy (NAT) and resection, similar to that of primary resectable cases (2-4). While the concept of NAT has been widely picked up with much enthusiasm, there is still a harsh debate and skepticism about the role of surgical resection, veiled in concerns about safety and insatiable level of evidence coming from the retrospective studies providing the data. Local ablative techniques that do not need to test surgical dexterity are more easily being accepted even if data comes from similar type of studies.

Regarding safety of surgery for LAPC - the morbidity and mortality of more advanced resections and vascular reconstructions have gradually improved throughout the years in designated centers reaching outcome that is almost comparable to that of standard resections (2-5). Surgery for LAPC, though, is at this point not yet standardized to allow for larger prospective randomized trials to take place that would require the participation of multiple centers. The principles of safe complex surgery, however, slowly precipitate and will allow these studies to happen in the near future. The necessity for this is undoubted as no local ablative technique up to this point has shown even near potential to improve long-term survival as much has surgical resection. By moving locally advanced cases into the resectable "pool" not only the overall survival of PC may be boosted, but it will grant more patients the long aspired chance for cure.

The possibility to resect LAPC with comparable long-term survival as resectable or borderline resectable disease after NAT, also raises the question whether the current classifications of local resectability make sense in the context of potent multimodality treatment (4). Besides, the concordance of reproducibility seems to be poor (6). Is the intermediate stage of borderline resectability clinically motivated at all? As NAT for PC is steadily making its way as the new standard of treatment for localized PC, the clinical entities will also need to adapt. Localized PC that is well controlled by NAT would either be technically easy or technically more challenging to resect. In the latter case we will need to adapt surgically to overcome the technical difficulties.

In the time of rapidly emerging data on the feasibility of surgery in LAPC, this specialized edition of fournal of Gastrointestinal Oncology seeks to summarize and critically evaluate the existing data on the topic and to provide a guidance for best clinical practice for surgical resection and oncologic treatment of LAPC.

\section{Acknowledgments}

Funding: None.

\section{Footnote}

Provenance and Peer Review: This article was commissioned by the editorial office, Fournal of Gastrointestinal Oncology for the 
series "Surgery for Locally Advanced Pancreatic Cancer". The article did not undergo external peer review.

Conflicts of Interest: The author has completed the ICMJE uniform disclosure form (available at https://dx.doi.org/10.21037/ jgo-21-542). The series "Surgery for Locally Advanced Pancreatic Cancer" was commissioned by the editorial office without any funding or sponsorship. EBR served as the unpaid Guest Editor of the series. EBR reports honoraria by ESGAR for invited expert lectures during workshops, unrelated to current series. The author has no other conflicts of interest to declare.

Ethical Statement: The author is accountable for all aspects of the work in ensuring that questions related to the accuracy or integrity of any part of the work are appropriately investigated and resolved.

Open Access Statement: This is an Open Access article distributed in accordance with the Creative Commons AttributionNonCommercial-NoDerivs 4.0 International License (CC BY-NC-ND 4.0), which permits the non-commercial replication and distribution of the article with the strict proviso that no changes or edits are made and the original work is properly cited (including links to both the formal publication through the relevant DOI and the license). See: https://creativecommons.org/ licenses/by-nc-nd/4.0/.

\section{References}

1. 1. Cancerfonden (2019). Statistik om cancer. Available online: https://www.cancerfonden.se/om-cancer/statistik

2. Del Chiaro M, Rangelova E, Halimi A, et al. Pancreatectomy with arterial resection is superior to palliation in patients with borderline resectable or locally advanced pancreatic cancer. HPB (Oxford) 2019;21:219-25.

3. Tee MC, Krajewski AC, Groeschl RT, et al. Indications and Perioperative Outcomes for Pancreatectomy with Arterial Resection. J Am Coll Surg 2018;227:255-69.

4. Rangelova E, Wefer A, Persson S, et al. Surgery Improves Survival After Neoadjuvant Therapy for Borderline and Locally Advanced Pancreatic Cancer: A Single Institution Experience. Ann Surg 2021;273:579-86.

5. Loos M, Kester T, Klaiber U, et al. Arterial Resection in Pancreatic Cancer Surgery: Effective After a Learning Curve. Ann Surg 2020. [Epub ahead of print]. doi: 10.1097/SLA.0000000000004054.

6. Giannone F, Capretti G, Abu Hilal M et al. Resectability of pancreatic cancer is in the eye of the observer. Ann Surg Open 2021. [Epub ahead of print]. doi: 10.1097/AS9.00000000000000087.

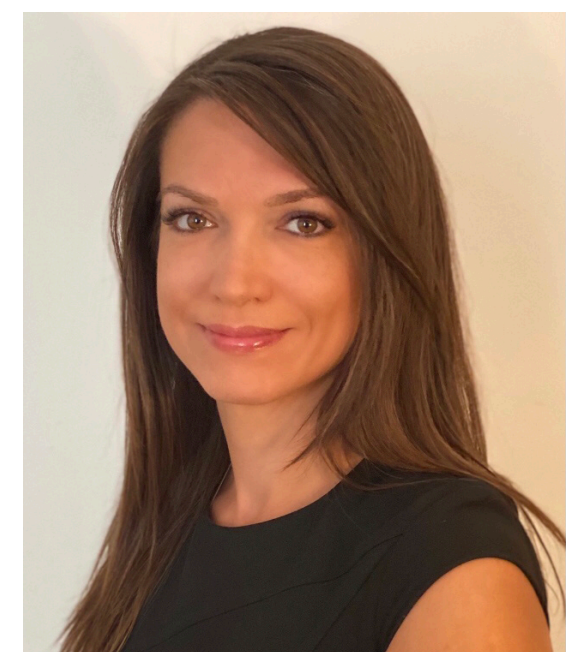

Elena B. Rangelova 
Elena B. Rangelova ${ }^{1,2}$, MD, PhD, FACS

${ }^{1}$ Department of Upper Abdominal Surgery, Sablgrenska University Hospital, Gothenburg, Sweden; ${ }^{2}$ Department of Surgery, The Institute of Clinical Sciences, Sablgrenska Academy, University of Gothenburg, Gothenburg, Sweden

(Email: elena.rangelova@gu.se)

Submitted Aug 23, 2021. Accepted for publication Sep 20, 2021.

doi: $10.21037 /$ jgo-21-542

View this article at: https://dx.doi.org/10.21037/jgo-21-542

Cite this article as: Rangelova EB. Locally advanced pancreatic cancer-a resectable disease? J Gastrointest Oncol 2021;12(5):2447-2449. doi: 10.21037/jgo-21-542 